\title{
Nöroloji Yoğun Bakım Ünitesinde Beyin Ölümü Tanısı Konulan Olguların İncelenmesi
}

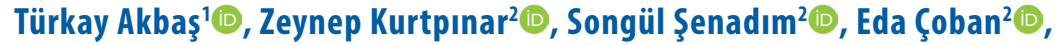 \\ Vildan Özkubat ${ }^{3}$, Sünkar Kaya Bayrak³ ${ }^{3}$, Hatice Ateş Güllï̈ , Belgin Mutluay², \\ Aysun Soysal² ${ }^{2}$, Sevim Baybaş², Dilek Ataklı²
}

'Düzce Üniversitesi Tıp Fakültesi, İç Hastalıkları Anabilim Dalı, Yoğun Bakım Bilim Dalı, Düzce, Türkiye ${ }^{2}$ Bakırköy Ruh Sinir Hastalıkları Eğitim ve Araştırma Hastanesi, Nöroloji Kliniği, Bakırköy, Türkiye ${ }^{3}$ Bakırköy Ruh Sinir Hastalıkları Eğitim ve Araştırma Hastanesi, Nöroloji Yoğun Bakım, Bakırköy, Türkiye

Türkay Akbaş, Dr. Öğr. Üyesi Zeynep Kurtpınar, Asistan Dr. Songül Şenadım, Uzm. Dr. Eda Çoban, Uzm. Dr. Vildan Özkubat, Uzm. Dr. Sünkar Kaya Bayrak, Uzm. Dr. Hatice Ateş Güllü, Uzm. Dr. Belgin Mutluay, Doç. Dr. Aysun Soysal, Doç. Dr. Sevim Baybaş, Doç. Dr. Dilek Ataklı, Doç. Dr.

\section{Not: Bu çalışma 29. Avrupa Yoğun} Bakım Derneği'nin kongresinde (ESICM 29th Annual Congress, 3-7 October 2015, Berlin) poster olarak sunulmuştur.

\section{Iletişim:}

Dr. Öğr. Üyesi Türkay Akbaş Düzce Üniversitesi Tıp Fakültesi, İc Hastalıkları Anabilim Dalı, Yoğun Bakım Bilim Dalı, Düzce, Türkiye

Tel: +903805421390

E-Posta: turkayakbas@yahoo.com

Gönderilme Tarihi : 29 Mart 2017

Revizyon Tarihi : 27 Mayıs 2017

Kabul Tarihi : 01 Haziran 2017
ÖZET

Amaç: Ülkemizde kadavradan organ naklinin düşük olmasının önemli nedeni yoğun bakım ünitelerinde (YBÜ) çalışan klinisyenlerin beyin ölümü (BÖ) tanısını koymaya odaklanmamasıdır. Bu çaıışmada nöroloji yoğun bakım ünitesinde BÖ tanısı konulan vakaların incelenmesi planlanmıştır.

Hastalar ve Yöntem: Bu çalışmada Bakırköy Ruh Sinir Hastalıkları Eğitim ve Araştırma Hastanesi nöroloji YBÜ'de bir yll içinde Bö tanısı konmuş 23 erişkin vaka retrospektif olarak değerlendirilmiştir.

Bulgular: Vakalarımızın \%56.3'ü erkek olup, yaş ortalaması $62+14$ sene olarak bulunmuş, yatış tanıları iskemik inme (\%52.2), intrakranial kanama (\%39.2), sinüs trombozu (\%4.3) ve hipoksik ensefalopati (\%4.3) idi. YBÜ'ye alındıktan sonra BÖ tanısı konulmasına kadar geçen süre 27.5 (10.6-135) saat bulunmuştur. $B O ̈$ tanısını düşündüren klinik bulgular, beyin sapı arefleksisi, Glasgow koma skor düşüklüğü, spontan solunum kaybı ve poliüridir. BÖ tanısı 13 vakada YBÜ uzmanı ile anestezi ve reanimasyon uzmanı tarafından, 10 hastada ise nöroloji uzmanı tarafından ilk olarak düşünülüp tanı işlemlerine gidilmiştir. BÖ tanısı 15 olguda apne testi ve nörolojik muayeneyle konulmuştur. Beş olguda apne testinin yapılamaması ve üç olguda tanıyı desteklemek için ek testler yardımıyla tanıya gidilmiştir. Vakaların $\% 95.5^{\prime}$ inde hipotansiyon, $\% 78$ 'inde diabetes insipidus ve $\% 61.9^{\prime}$ unda hipotermi gelişmiş ve uygun tedavileri yapılmış̧ı. Olgularımızın \%13'ü donör olmuştur.

Sonuç: YBÜ'de vaka takibi yapan doktor ve hemşirelerin beyin ölümünü tanıma ve donör bakımı konusunda eğitimli olması ile BÖ tanısının konulması oranı ve bunun sonucunda kadavradan organ nakli sayısı artacaktır.

Anahtar sözcükler: Apne testi, diabetes insipidus, donör, Glasgow koma skoru

\section{ANALYSIS OF THE PATIENTS WHO HAD BRAIN DEAD DIAGNOSIS IN A NEUROLOGICAL INTENSIVE CARE UNIT} ABSTRACT

Objectives: The main reason why we have insufficient organ donation from cadavers in our country is the lack of focus on brain death (BD) by the clinicians working in the intensive care unit (ICU). The aim of this study was to analyze patients diagnosed with $B D$ in a neurological ICU.

Patients and Methods: We retrospectively analyzed twenty-three patients who had been diagnosed within the year by BD in the Neurological ICU of Bakirköy Research and Training Hospital for Psychiatry, Neurology and Neurosurgery.

Results: The mean age was $62+14$ and $56.3 \%$ were male. The admission diagnoses were ischemic infarction $(52.2 \%)$, intracerebral hemorrhage (39.2\%), sinus thrombosis (4.3\%) and hypoxic encephalopathy (4.3\%). The time interval between ICU admission and BD diagnosis was 27.5 hours. The signs leading to BD were brainstem areflexia, decreased Glasgow coma score, loss of spontaneous breath and polyuria which were noticed first by the neurologists in 10 subjects and by the intensive care specialists and anaesthesiologists in 13 subjects. BD decisions in 15 patients were given by apnea testing and neurologic examination. Further tests were conducted in five patients because of inability to perform apnea tests whereas neurologists ordered additional tests in three patients. The rates of hypotension, diabetes insipidus and hypothermia were $95.5 \%, 78 \%$ and $61.9 \%$, respectively, and they were managed properly. Organ donation rate was $13 \%$.

Conclusion: The doctors and nurses working in an ICU should be trained on how to recognize $B D$ and to manage potential organ donors. This will improve BD diagnosis and increase organ donations.

Key words: Apnea testing, diabetes insipidus, donation, Glasgow coma score 
rgan nakilleri canlı donör veya kadavradan yapılmaktadır. Kadavra organ temini için en önemli kaynaktır. Canlı kişiden organ alımı vericiyi sağlık açısından risk altına sokabileceğinden Avrupa ülkelerinde ve Amerika'da olduğu gibi ülkemizde de kadavradan organ nakillerin yaygınlaşması gereklidir. Aynı zamanda kalp, pankreas, akciğer, ince bağırsak ve kornea sadece kadavradan elde edilebilen organlardır. Kadavradan organ naklinin yapılabilmesi için öncelikle beyin ölümü (BÖ) tanııının konulması gereklidir. "Beyin ölümü" merkezi sinir sisteminin kafatası içinde kalan kısmı olan beyin, beyin sapının ve serebellumun tamamının tüm aktivitelerinin kalıcı, yani geri dönüşümsüz olarak yitirilmesidir (1). Beyin ölümü kavramı ilk defa 1959 da tanımlanmıştır. 1968 yılında Harvard Kriterleri oluşturularak BÖ tanısı standardize edilmiştir (2). Birçok ülkede beyin ölümü için yapılmış protokoller vardır ve bu protokoller ülkeler arasında bazı farklılık gösterebilir $(2,3)$. Ülkemizde BÖ tanı kriterleri Sağlık Bakanlığı tarafından tanımlanmıştır; derin koma nedenini açıklayacak bir klinik durumla beraber vakada beyin sapı reflekslerinin olmaması, spontan solunum çabasının bulunmaması ve apne testinin pozitif saptanmasıyla tanı konulmaktadır (4). Şüphe durumunda ise beyin kanlanmasını veya aktivitesini gösteren bilgisayarlı tomografi anjiografi (BTA), transkranial doppler, manyetik rezonans anjiografi ve elektroensefalografi (EEG) teknikleri kullanılabilir $(5,6)$. BÖ tanısı biri nöroloji veya beyin cerrahisi uzmanı, diğeri de yoğun bakım veya anesteziyoloji ve reanimasyon uzmanı olmak üzere iki uzmanın oy birliği ile konulabilmektedir (7). Yoğun bakım alanında tüm gelişmelere rağmen, BÖ tanısı ve organ bağışı sayısındaki yetersizlikler, organ nakli bekleyen hastalar için en ciddi problem olarak karşımızda durmaktadır. Bu çalışmada Bakırköy Ruh Sinir Hastalıkları Eğitim ve Araştırma Hastanesi nöroloji yoğun bakım ünitesinde (YBÜ) BÖ tanısı konulan olguların retrospektif olarak incelenmesi planlanmıştır.

\section{Gereç ve yöntemler}

Bu çalışmada Nisan 2014 - Nisan 2015 tarihleri arasında Bakırköy Ruh Sinir Hastalıkları Eğitim ve Araştırma Hastanesi nöroloji YBÜ'de BÖ tanısı konulan hastalar retrospektif olarak incelenmiştir. Beyin ölümü tanısı Sağlık Bakanlığı tarafından 01.02.2012 tarihli resmi gazetede yayınlanan kriterlere göre konulmuştur (4). Bu süre içinde Nöroloji YBÜ 15'i üçüncü basamak ve 8'i ikinci basamak olmak üzere toplam 23 yatağı bulunan iki YBÜ'den oluşmaktaydı. Tüm hastalar her gün nöroloji uzmanı ve yoğun bakım yan dal uzmanı veya anestezi ve reanimasyon uzmanı tarafından değerlendirilirdi. Nöroloji YBÜ'ye yatırılan hastalardan gerekli klinik durumlarda beyin cerrahisi konsültasyonu da istenilirdi.
Hastaların demografik özellikleri, yatış tanıları, ilk yatış ile BÖ tanı arasında geçen süre, BÖ klinik şüphesinin başladığı andan tanıya gidilene kadar gecen süre, donör olmayan olguların BÖ tanısı konulduktan sonra kardiyak arrest gelişene kadar geçen süre, BÖ tanısı için kullanılan testler, organ bağış oranı, kullanılan tedaviler, vital bulguları ve BÖ tanısı konulmadan bir gün önce ve tanı günü bakılan biyokimya sonuçları kaydedilmiştir. Organ koordinatör hemşiresi beyin ölümü ve aile görüşmesiyle ilgili gerekli eğitim programlarına katılmıştır. Nöroloji, yoğun bakım ve anestezi ve reanimasyon uzmanları da uzmanlık eğitimleri sırasında BÖ ile ilgili eğitimlerini almışlardır. Etik onay, Bakırköy Ruh Sinir Hastalıkları Eğitim ve Araştırma Hastanesinin 05.05.2015 tarih ve 20569 sayılı kararı ile alınmıştır.

Veriler SPSS 18 yazılımı kullanılarak yapılmıştır. Normal dağılımı olmayan değişkenler için Mann-Whitney $U$ ile Wilcoxon testi kullanılmış ve sonuçlar ortanca ile $\% 25$ ve 75 çeyreklerle ifade edilmiştir. Normal dağılımı olan veriler için Student $t$ test kullanılmış ve sonuçlar ortalama ve stardart sapma (SD) ile belirtilmiştir. Kategorik veriler için $X^{2}$ kare testi kullanılmış ve sonuçlar yüzde olarak yazılmıştır. İstatistiksel anlamlılık için $P$ değeri $<0.05$ kullanılmıştır.

\section{Bulgular}

Toplam 23 olguya BÖ tanısı konulmuştur. Beyin ölümü tanısı konulan vakalarımızın 13'ü (\%56.3) erkek olup, yaş ortalaması $62 \pm 14$ sene olarak bulundu. Hastalarımızın, iskemik inme (n:12), intrakranial kanama (n:9), sinüs trombozu (n:1) ve hipoksik ensefalopati (n:1) tanıları ile yatışları yapılmıştır (Tablo 1). Bir hasta hariç tüm vakalar acil servisten yoğun bakım ünitesine alınmıştır. Olguların acil serviste hesaplanan Glasgow koma skoru (GKS) 9 (5-11) iken YBÜ yatışında ise 7 (5-9) olarak hesaplanmış ve istatistiksel olarak iki GKS skoru arasında anlamlı bir fark bulunmuştur $(p=0.036)$. Acil servisten YBÜ'ye alınana kadar geçen süre 1.7 (0.4-5.6) saat, YBÜ'ye alındıktan sonra BÖ tanısı konulana kadar geçen süre 27.5 (10.6-135) saat ve GKS 3'e düştükten sonra BÖ tanısı konulana kadar geçen süre 21.2 (6.3-58) saat olarak hesaplanmıştır. İskemik inme geçiren vakaların tamamı tromboliz alımına uygun kriterlere sahip değildi. Beyin cerrahisi tarafından vakaların hiçbirine akut dekompresyon ameliyatı önerilmemiştir.

Vakalarımızda BÖ olabileceğini düşündüren ilk bulguların, olguların 9'unda beyin sapı refleksleri alınamaması, 8'inde GKS'nin düşük olması, 4'ünde spontan solunumun olmaması ve 2'sinde poliürinin gelişmesi olduğu görülmüştür. BÖ tanısı 13 vakada YBÜ uzmanı ile anestezi ve reanimasyon uzmanı tarafından, 10 hastada ise nöroloji uzmanı 
Tablo 1. Vakaların demografik özellikleri, yatış tanıları ve BÖ düşündüren klinik bulguları

\begin{tabular}{lc} 
Parametreler & Sonuç/ar \\
\hline Yaş, (sene) & $62 \pm 14$ \\
Erkek, n (\%) & $13(56.4)$ \\
Yatış tanısı, n (\%) & \\
İskemik strok & $12(52.2)$ \\
İntrakranial kanama & $9(39.2)$ \\
Hipoksik ensefalopati & $1(4.3)$ \\
Transvers sinus trombozu & $1(4.3)$ \\
BÖ† tanısını düşündüren klinik bulgu, $\mathbf{n}$ (\%) & \\
Beyin sapı arefleksi & $9(39)$ \\
Düşük GKS† & $8(34.5)$ \\
Spontan soluma kaybı & $4(17.5)$ \\
Poliüri & $2(9)$ \\
Yatışta sırasında yapılan kranial & \\
radyolojik incelemeler, $\mathbf{n}$ (\%) & \\
BT† & $12(48)$ \\
Diffüzyon MR† & $9(36)$ \\
Diffüzyon MR, MR anjiografi & $2(8)$ \\
BT, diffüzyon MR, MR anjiografi & $1(4)$ \\
BT, diffüzyon MR & $1(4)$ \\
\hline tBö: beyin ölümü; GKS: Glasgow koma skoru; BT: bilgisayarlı tomografi; MR: \\
manyetik rezonans görüntüleme.
\end{tabular}

tarafından ilk olarak düşünülüp tanı işlemlerine gidilmiştir. On beş olguda BÖ tanısı apne testi ve nörolojik muayene ile konulmuştur. Sekiz vakada ise destekleyici testlere gerek duyulmuş ve 6 olguda BTA ile 2 olguda EEG yapılmıştır. Beş olguda apne testi yapılamadığı için, üç olguda ise nörolojik muayene sırasında ağrılı uyarana verilen yanıtın spinal refleks veya motor cevap ayırımı yapılamadığından ek testler uygulanmıştır. Apne testi öncesi tüm hastalar hemodinamik olarak stabil hale getirilmiş ve apne testi sırasında komplikasyon gelişmemiştir. Apne testi öncesi vital bulgular tablo 2'de gösterilmiştir.

Vakaların \%95.5'inde hipotansiyon geliştiği için vazopressör tedavisi başlanmıştır. Olguların \%78'inde ise diabetes insipidus (Di) görülmüş ve bu olguların $\% 40$ 'ına desmopressin tedavisi [6 (5-6) $\mathrm{mcg} / \mathrm{gün}$ ] verilmiştir. Metilprednisolon tedavisi \%56.5 [60 (36-60) mg/gün] ve levotiroksin tedavisi \%39 [300 mg (112-400) mcg tek doz] vakaya verilmiştir. Hipotermi $\left(<36.0^{\circ} \mathrm{C}\right) \% 61.9$ hastada görülmüş ve bu hastaların vücut ısıları ekstra tedbirlerle artırılmıştır. BÖ tanısı konulmadan bir gün önce ve konulduğu güne ait vücut ısıları, GKS ve laboratuvar değerleri kıyaslandığında, BÖ tanısı konulduğu gün bakılan vücut ısısının anlamlı düşük; sodyum ve ALT değerlerinin ise yüksek olduğu görülmüştür (Tablo 3). Vakalara BÖ tanısı konulana kadar geçen 24 saatlik zaman diliminde verilen SIVI 4980 (4070-6125) mililitre ve idrar miktarı 3475 (24404775) mililitre bulunmuştur
Tablo 2. Apne testi öncesi vakaların vital bulgular

\begin{tabular}{lc} 
Parametreler & Sonuçlar \\
\hline Sistolik KB, $(\mathrm{mmHg}) \dagger$ & $99(99-100)$ \\
Diyastolik KB, $(\mathrm{mmHg})$ & $66(51-92)$ \\
Vücut ISISI, $\left({ }^{\circ} \mathrm{C}\right)$ & $36(34.9-36.4)$ \\
Nabız, (dakika) & $86(74-104)$ \\
Solunum sayıSI, (dakika) & $12(12-17)$ \\
$\mathrm{O}_{2}$ satürasyonu, $(\%) \dagger$ & $99(98.6-100)$ \\
\hline${ }^{\dagger} \mathrm{KB}$, kan basıncl; ${ }_{2},{ }^{\text {oksijen. }}$ &
\end{tabular}

Tablo 3. Beyin ölümü konulmadan bir gün önceki ve tanı konulduğu günkü GSK, vücut ISISı ve laboratuvar değerlerinin kıyaslanması

\begin{tabular}{|c|c|c|c|}
\hline Parametreler ${ }^{\ddagger}$ & BÖ öncesi gün, & BÖ günü’,+ & $P$ \\
\hline GKS† & $3(3-5)$ & $3(3-3)$ & 0.017 \\
\hline Ateş (maks., ${ }^{\circ} \mathrm{C}$ ) & $37.8 \pm 1.3$ & $36.7 \pm 1.1$ & $<0.001$ \\
\hline Ateş (min., ${ }^{\circ} \mathrm{C}$ ) & $36.1 \pm 1.2$ & $35.5 \pm 0.8$ & 0.017 \\
\hline Sodyum, (mEq/L) & $146.5 \pm 11$ & $156.8 \pm 10.7$ & 0.004 \\
\hline Potasyum, (mEq/L) & $4.1 \pm 0.6$ & $3.8 \pm 0.7$ & 0.774 \\
\hline Kreatinin, (mg/dL) & $1.4 \pm 0.8$ & $1.7 \pm 0.8$ & 0.058 \\
\hline AST, (IU/L)† & $50(24-74)$ & $48(31-74)$ & 0.698 \\
\hline ALT, (IU/L)† & $32(20-61)$ & $42(25-128)$ & 0.011 \\
\hline Albümin, (gr/dL) & $3.6 \pm 1$ & $3.2 \pm 0.4$ & 0.117 \\
\hline Glukoz (maks., mg/dL) & 181 (147-322) & 274 (189-381) & 0.230 \\
\hline
\end{tabular}

‡Normal dağılımı olmayan değişkenler için ortanca ve çeyrekler, normal dağılımı olan değişkenler için ortalama ve SD değerleri alındı. SBeyin ölümü tanısından bir gün önce ile beyin ölümü formu imzalandığı gün bakılan sonuçlar birbiriyle kıyaslanmıştır. †BÖ, beyin ölümü; GKS, Glasgow koma skoru; AST, aspartat aminotransferaz; ALT, alanin aminotransferaz.

Ailelere BÖ'nün deklerasyonu tüm vakalar için doktorlar tarafından yapılmış fakat organ istemi için aile görüşmesi 18 olguda organ nakli koordinatör hemşiresi tarafından, 4 olguda ise vakayı takip eden doktor ve organ nakli koordinatör hemşiresi tarafından yapılmıştır. Vakaların ancak 3'ü (\%13) donör olmuştur. Donör olmayan vakalarda BÖ tansı konulduğu an ile kardiyak arrest gelişene kadar geçen ortanca süre 2 (1-10.6) saat bulunmuştur. Bir vakada aile ile organ bağışı görüşmesi yapıldığı sırada kardiyak arrest gelişmiştir.

\section{Tartışma}

Tedavisi ve yaşamı organ nakline bağlı olan hastalar için organ temini ülkemiz için önemli bir sağlık sorunudur. Canlı vericiden sadece böbrek ve karaciğer alınabilmektedir. Oysa tek organ olan kalp, akciğer, pankreas gibi organların temini sadece kadavradan sağlanabilmektedir. 
Türkiye'de organ naklinin önündeki en önemli sorun BÖ tanısı konulmadan vakaların kaybedilmesidir. Tanı konulamama nedeni bilgi eksikliği olduğu gibi hekimlerin BÖ teşhisini koymada yaşadıkları tereddüt de olabilir. BÖ tanı kriterlerinde ulusal ve uluslararası standardizasyon sağlanmıştır $(2,4)$. BÖ tanısı için etkin çalışan bir ekibe intiyaç vardır. Birçok hastanelerde özel olarak görevlendirilmiş koordinatörler aracılığıyla tanı sürecin etkin ve hızlı bir şekilde ilerlemesi amaçlanmaktadır. Hastanemizde de yoğun bakım yan dal, nöroloji ve anestezi ve reanimasyon uzmanları ile koordinatör ve yoğun bakım hemşirelerinden oluşan faal bir ekiple BÖ tanısının atlanmadan hızlı bir şekilde konulması sağlanmıştır.

Diğer çalışmalarda BÖ tanısı ortalama 3 günde konulurken bizin çalışmamızda bu süre bir gün olarak bulundu (8). Çalışmamızda vakalar, acil servisten YBÜ'ye çok kısa sürede alınmışlar. YBÜ'ye yatışla BÖ tanısı konulana kadar geçen ortanca süre 27.5 saat ve GKS 3'e düştükten sonra BÖ tanısı konulana kadar geçen süre ise 21 saattir. Hastalarımızın tamamının ciddi nörolojik nedenlerle hastaneye başvurmuş olmalarının BÖ'nün hızlı gelişmesinin en önemli nedeni olduğu düşünülmüştür. Olguların acil servisten YBÜ yatışına kadar gecen kısa zaman diliminde GKS'lerinde anlamlı bir düşme olduğu saptanmıştır. Bu bulgu vakalardaki nörolojik progresyonun hızlı olduğunu desteklemektedir. En önemlisi ise olguların yaklaşık 2 saat gibi kısa sürede YBÜ'ye yatışları sağlanarak solunum ve hemodinamik destekler verildiğinden kardiyak arrest gelişmesi engellenmiş ve böylece kısa sürede BÖ tanısı konulabilmiştir. Hastanemizde tüm kranial görüntülerin çekilebildiği tam gün çalışan bir radyoloji bölümünün olması ve EEG laboratuvarı ile eğitimli ekibinin bulunması yardımcı testlerin hızlı bir şekilde sonuçlanmasını sağlamıştır. Mevcut alt yapının olması da kısa sürede BÖ tanısını koymada katkısı olduğunu düşünmekteyiz.

Vakalarımızın ancak 3'ü (\%13) donör olmuştur. Tüm dünyada aile onayı \%30-40 oranındadır (9). Türkiye'de yapılan diğer çalışmalarda bu oran \%29 ile \%64 arasında rapor edilmiştir $(8,10,11)$. Kıraklı ve arkadaşlarının İzmir'de yaptıkları çalışmalarında \%64 olarak oldukça yüksek bir oran saptanmıştır. Aynı yayında İzmir bölgesinde donör oranının da Türkiye'nin 3 katı olduğu belirtilmiştir (11) Sağlık Bakanlığı verilerine göre 2014 yılında 1587 beyin ölümü bildirilmiş ve bu vakaların 364'ü donör olmuştur. 2015 yılında ise 1969 beyin ölümü vakasının 472'sinin donör olduğu bildirilmiştir. Türkiye ortalamasının da \%22-24 olduğu görülmektedir. Bizim donör oranımız bu verilere kıyasla daha düşük bulunmuştur. Kadavra organ temininde en önemli merkezler bünyesinde yoğun bakım üniteleri bulunan travma merkezleridir. Battal ve arkadaşlarının çalışmasında travmanın beyin ölümü tespit edilen hastalar arasındaki oranı \%58 olarak rapor edilmiştir (10). Bizim hastanemiz özel dal hastanesi olduğundan ve ünitemizde travma hastası takip edilmediğinden bu oran daha düşük olabilir. Diğer çalışmalarda BÖ gelişen vakaların yaş ortalamaları 40-48 yıl arasında seyrederken bizim çalışmamızda yaş ortalaması 62 olarak bulunmuştur $(8,10,11)$. Burada nöroloji yoğun bakım ünitesi olmamızın rolü önemlidir. Serebrovasküler olaylar (SVO) genelde 60 yaş ve üstü hastalarda görülür (12). Nöroloji yoğun bakım ünitemizde de ağırık olarak SVO gelişen hasta yatışları olduğundan yaş ortalamamız yüksek bulunmuştur. Ünitemiz özelinde önemli bir sorun da hastalarımız yaşlı olduğundan birinci derece yakınlarının da yaşlı olması, hasta ile daha uzak akrabalarının ilgilenmesi ve organ nakline izin verebilecek birinci derece akrabalarla görüşmede gecikme olmasıdır. Bununla beraber BÖ tanısı artıkça aile ile görüşme tecrübemizin de artacağını ve dolayısıyla takibinde donör sayımızda da anlamlı bir yükselme olacağını düşünmekteyiz.

BÖ gelişen hastalarda hipotansiyon ve Di sık görülmektedir. Hipotansiyon \%74 ile \%88 $(11,13)$ arasında bildirilmektedir. Bizim çalışmamızda da bir hasta hariç tüm hastalarda hipotansiyon görülmüş ve hepsine vazopressör tedavisi başlanmış. Di ise \%46 ile \%87 $(13,14)$ oranında bildirilmektedir. Bizim çalışmamızda Di oranı literatüre benzer şekilde \%78 olarak bulundu. Vakalarımızın yarısından fazlasında hipotermi görülmüştür ve bu vakalara ısıtma işlemleri uygulanmıştır (13). Olgularımızın BÖ günü bakılan serum sodyum değerleri yüksek bulunmuştur. Vakalarımızdaki hiperrnatreminin Di'aya ikincil serbest su kaybının fazla olmasına bağlı geliştiği düşünülmektedir. BÖ günü bakılan serum kreatinin değerindeki yüksekliğinin de Di'aya ikincil gelişen hipovolemiye bağlanıldı. Bu olguların tedavisine BÖ günü yaklaşık 5000 mililitre mayi verilerek sıvı dengesinin pozitifte bırakılması sağlanmıştır.

Bu çalışmanın önemli kısıtlayıcı tarafı retrospektif olmasıdır. İkinci önemli kısıtlayıcı neden ise vaka sayımızın düşük olmasıdır. Üçüncü neden ise ülkemizde oldukça az sayıda olan sadece nöroloji hastalarına özel bir dal hastanesinin YBÜ'sünde BÖ tanısı konulan hastaların değerlendirilmiş olmasıdır. Bu nedenlerden dolayı çalışma sonuçlarını tüm ülkeye genellemek mümkün olmayabilir.

\section{Sonuç}

BÖ tanısı yoğun bakım ünitelerinde konulmaktadır ve YBÜ'de vaka takibi yapan doktor ve hemşirelerin beyin 
ölümünü tanıma ve donör bakımı konusunda eğitimli olması gereklidir. Kıraklı ve arkadaşlarının çalışmasında görüldüğü gibi organ bağışı yapan vakaların aileleri ile görüşüldüğü zaman, \%36'sı önceden de olumlu baktıklarını bildirirken, \%64'ü bunu koordinatörün etkisine

\section{Kaynaklar}

1. Novitzky D, Cooper DKC. The Brain-Dead Organ Donor. New York: Springer, 2013: 13-20. [CrossRef]

2. Gardiner D, Shemie S, Manara A, Opdam H. International prospective on the diagnosis of death. Brit J Anaesthesia 2012;108 (Suppl 1):i14-i28. [CrossRef]

3. Wijdicks EF. Brain death worldwide. Accepted fact but no global consensus in diagnostic criteria. Neurology 2002;58:20-5.

4. Organ ve doku nakli hizmetleri yönetmeliği. Resmi Gazete 01.02.2012 - 28191 .

5. Wijdicks EF. Brain death guidelines explained. Semin Neurol 2015;35:105-15. [CrossRef]

6. Young GB, Lee D. A critique of ancillary tests for brain death. Neurocritical Care 2004;1:499-508. [CrossRef]

7. Organ ve doku alınması, saklanması, aşılanması ve nakli hakkında kanun. Kanun numarası 6514 Resmi Gazete 18.01.2014 - 28886.

8. Karasu D, Yılmaz C, Karaduman I ve ark. Beyin ölümü olguların retrospektif incelenmesi. Yoğun Bakım Dergisi 2015;6:23-6. [CrossRef] bağlamışlardır (11). Bu nedenle, aile onayı alacak olan organ nakli koordinatörlerinin de eğitimli olması ve hastanın sorumlu hekimi ile sıkı bir işbirliği içinde çalışması gerekmektedir. BÖ tanısı arttıkça potansiyel organ donör sayısı da artacaktır.
9. Jansen $\mathrm{NE}$, van Leiden $\mathrm{HA}$, Haase-Kromwijk BJ, Hoitsma AJ. Organ donation performance in the Netherlands 2005-08; medical record review in 64 hospitals. Nephrol Dial Transplant 2010;25:1992-7. [CrossRef]

10. Battal $M$, Horoz $A$, Karatepe O ve ark. Beyin ölümü tespitinde araştırma hastanesi deneyimi. Şişli Etfal Hastanesi Bülteni 2013;47:59-62.

11. Kıraklı C, Uçar ZZ, Anıl AB ve ark. Yoğun bakım'da beyin ölümü kesin tanı süresinin kısalmasının organ bağışı oranlarına etkisi. Yoğun Bakım Dergisi 2011;1:8-11. [CrossRef]

12. Johnston SC, Amarenco P, Albers GW, et al. Ticagrelor versus aspirin in acute stroke or transient ischemic attack. N Engl J Med 2016;375:3543. [CrossRef]

13. Döşemeci L, Yılmaz M, Cengiz M, Dora B, Ramazanoğlu A. Brain death and donor management in the intensive care unit: Experiences over the last 3 years. Transplant Porc 2004;36:20-1. [CrossRef]

14. Youn TS, Greer DM. Brain death and management of a potential organ donor in the intensive care unit. Crit Care Clin 2014;30:813-31. [CrossRef] 